\title{
Analysis of Soil Fertility Quality and Heavy Metal Pollution in the Dawen River Basin, China
}

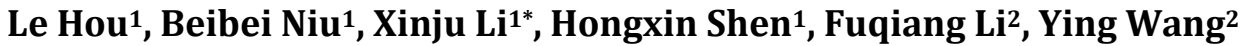 \\ ${ }^{1}$ College of Resources and Environment, Shandong Agricultural University, Taian, China \\ ${ }^{2}$ The Third Exploration Team of Shandong Coalfield Geologic Bureau, Taian, China \\ Email: *1xj0911@126.com
}

How to cite this paper: Hou, L., Niu, B.B. Li, X.J., Shen, H.X., Li, F.Q. and Wang, Y. (2020) Analysis of Soil Fertility Quality and Heavy Metal Pollution in the Dawen River Basin, China. Open Journal of Soil Science, 10, 602-615.

https://doi.org/10.4236/ojss.2020.1012029

Received: November 30, 2020

Accepted: December 28, 2020

Published: December 31, 2020

Copyright (c) 2020 by author(s) and Scientific Research Publishing Inc. This work is licensed under the Creative Commons Attribution International License (CC BY 4.0).

http://creativecommons.org/licenses/by/4.0/

\begin{abstract}
Understanding the soil fertility status and heavy metal pollution is of great significance for targeted environmental management and governance in a basin. The Dawen River Basin (DRB), a sub-basin in the lower Yellow River area in China, was taken as the study area. A total of 107 surface soil samples were collected in the DRB in October 2019, and the sampling points were mainly located within $10 \mathrm{~km}$ of the mainstream of the Dawen River. Based on the measured soil nutrient indicators (organic matter, total nitrogen, total phosphorus, and total potassium) and heavy metal contents (As, $\mathrm{Hg}, \mathrm{Cd}, \mathrm{Cr}$, and $\mathrm{Pb}$ ), the status and spatial distribution of soil fertility and heavy metal pollution in the DRB were evaluated by combining the use of the Nemerow index method, the land accumulation index method, and the general Kriging interpolation method. The results showed that the soil fertility in the DRB was generally at a normal level or below, while some areas of Taian City, Xintai City, and Ningyang County had relatively high soil nutrient content. The content of heavy metals in the soil of the DRB was mainly at a safe level, but the single pollution index and geo-accumulation index implied that there was light to moderate pollution of heavy metals in individual samples, and the content of heavy metals in urban and industrial agglomerations is relatively high.
\end{abstract}

\section{Keywords}

Soil Fertility, Heavy Metal Pollution, Spatial Distribution, Dawen River Basin

\section{Introduction}

The river ecosystem is a channel connecting the material and energy exchanges between the land and the ocean, which plays an important role in the circulation of the biosphere [1]. The quality of the soil environment along the river banks 
closely affects the growth of vegetation and the safety of human life in the basin. Meanwhile, it is of great significance for the river water quality and the ecological environment condition along the river banks [2] [3] [4]. In recent years, increasing attention has been made to the ecological environment of riparian soil and the research regarding soil fertility and pollution. Sigua et al. [5] [6] evaluated the soil quality along the rivers in the southern United States and found that the heavy metal content and other soil indices showed a healthy state. Pinedo et al. [7] used pollution factors, enrichment factors, and land accumulation index to assess riparian soil pollution. The results showed that there was a high concentration of $\mathrm{Ni}$ in the soil, which may be related to agricultural irrigation and mining activities. Liu et al. [8] systematically studied the assessment of soil fertility and environmental quality along rivers via monitoring and analyzing soil quality indices. Besides, Liang et al. [9] evaluated the potential ecological risk of the soil along the Kui River and found that there existed excessive-high heavy metals in parts of the study area, and its soil ecological risk exceeded the normal range.

As the largest tributary of the lower Yellow River in Shandong Province, the Dawen River runs through the whole Taian area from east to west and is the only river flowing into Dongping Lake. The water quality and soil ecological environment will inevitably affect the production activity and human living in the basin [10]. With the rapid development of the urban economy, the rise of industry, and the expansion of agriculture, more and more waste-water and pollutants are discharged into the Dawen River, which poses great threats to the ecological environment of the Dawen River Basin [11]. At present, the research on the Dawen River Basin is mainly focused on the ecological hydrological changes and the evaluation of water pollution [12] [13] [14]. However, researches on the soil quality evaluation in the basin related to soil fertility and soil environment along the Dawen River are still lacking. Therefore, field sampling and laboratory testing were combined used in this study to evaluate the soil fertility quality and soil environmental quality of the Dawen River Basin (DRB), aiming at providing data support for in-depth study of the ecological environment of the DRB and theoretical basis for the restoration of ecological function in Dawen River Basin.

\section{Materials and Methods}

\subsection{Study Area}

The Dawen River is one of the most important rivers in Shandong Province. It is located in the southern part of Mount Tai and the right bank of the Yellow River, which lies between $116^{\circ}-118^{\circ} \mathrm{E}$ and $35.7^{\circ}-36.6^{\circ} \mathrm{N}$. The Dawen River originated from Yiyuan County, Shandong Province. The river flows from east to west through Laiwu, Xintai, Taian, Feicheng, and Dongping, then flows into Dongping Lake, and finally flows into the Yellow River from Chenshankou [15]. The Dawen River has a total length of $208 \mathrm{~km}$ and a total drainage area of 8633 $\mathrm{km}^{2}$. The upper, middle and lower reaches are divided by Dawenkou and Dai- 
cunba as the dividing point. The upper reaches of the Dawen River Basin are the main water catchment area with low hills and relatively fertile soil; the middle and lower reaches are mostly plains, with sandy soil and sandy loam soil occupying a relatively high proportion, which has good heat preservation and moisture retention properties and is suitable for the development of agriculture.

\subsection{Soil Sampling and Measurements}

A total of 107 soil samples were collected in October 2019, with the sampling sites mainly within 10 kilometers on both sides of the mainstream of the Dawen River (Figure 1). At each site, soil sample was collected with five replicates using a diagonal sampling method, which were then mixed and homogenized. The sampling depth was set to the upper soil horizon $(0-20 \mathrm{~cm})$ with the removal of the surface litter. All samples were stored in polyethylene bags and brought back to the laboratory for measurements.

Each sample was tested for 10 soil fertility and pollution indicators, including $\mathrm{pH}$, soil organic matter (SOM), total nitrogen (TN), total phosphorus (TP), Total potassium $(\mathrm{TK})$, and 5 heavy metals $(\mathrm{Cd}, \mathrm{Hg}, \mathrm{As}, \mathrm{Pb}, \mathrm{Cr})$. The testing process is carried out in accordance with the corresponding standards.

\subsection{Comprehensive Evaluation of Soil Fertility}

Evaluation of soil fertility in the Dawen River Basin was carried out using a revised Nemerow composite index method, which serves as a useful tool for soil fertility evaluation [16].

\subsubsection{Determining the Standard of Soil Factor Classification}

The classification standard of soil factors was determined mainly according to

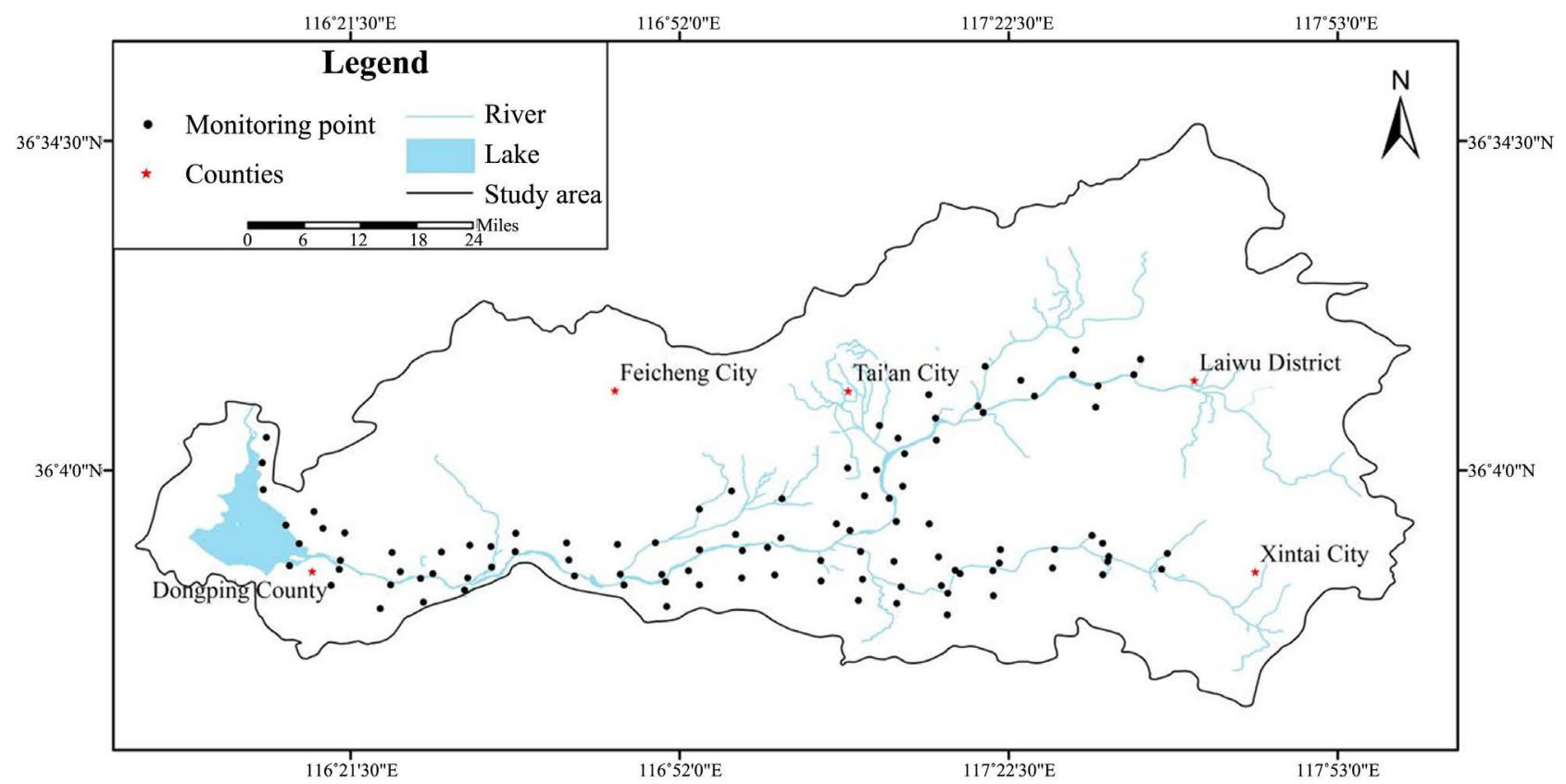

Figure 1. Distribution of soil sampling sites in the study area. 
the Nutrient Classification Standard of China's Second National Soil Census and the Technical Specification for Soil Analysis. Besides, the actual situation of the Dawen River Basin was also considered. The specific classification standard value for SOM, TN, TP, TK and pH were listed in Table 1.

\subsubsection{Standardization of Soil Indicator Value}

Different soil indicators have different dimension ranges, and calculating them directly will lead to meaningless results. Therefore, the measured values of the 5 soil indicators were standardized according to their classification standards, so as to eliminate the dimensional difference between the indicators. The standardization formula was as follows:

$$
\begin{gathered}
\text { when } C_{i} \leq X_{a}, P_{i}=\frac{C_{i}}{X_{a}}\left(P_{i} \leq 1\right) \\
\text { when } X_{a}<C_{i}<X_{c}, P_{i}=1+\frac{C_{i}-X_{a}}{X_{c}-X_{a}}\left(1<P_{i}<2\right) \\
\text { when } X_{c}<C_{i}<X_{p}, P_{i}=2+\frac{C_{i}-X_{c}}{X_{p}-X_{c}}\left(2<P_{i}<3\right) \\
\text { when } C_{i}>X_{p}, P_{i}=3
\end{gathered}
$$

where $C_{i}$ is the actual measured value of the soil indicators; $X_{a}, X_{c}$ and $X_{p}$ indicate the classification standard value for soil indicators; $P_{i}$ is the standardized soil fertility coefficient of the measured soil indicator value.

\subsubsection{Calculation of the Comprehensive Soil Fertility Coefficient}

The comprehensive soil fertility coefficient was calculated based on the revised Nemerow index method, the formula of which was as follows:

$$
P=\sqrt{\frac{\left(P_{\text {imean }}\right)^{2}+\left(P_{i \text { min }}\right)^{2}}{2}} \times \frac{(n-1)}{(n)}
$$

where $P$ is the comprehensive soil fertility coefficient; $P_{\text {imean }}$ is the average value of the standardized soil fertility coefficient for different soil indicators; $P_{\text {min }}$ is the minimum value of the standardized soil fertility coefficient; and $\mathrm{n}$ is the number of soil indicators.

\subsection{Evaluation of Soil Heavy Metal Pollution}

Nemerow comprehensive pollution index method and Geo-accumulation index method was used in the soil heavy pollution evaluation and classification.

Table 1. Classification standard for soil factors.

\begin{tabular}{ccccccc}
\hline $\begin{array}{c}\text { Classification } \\
\text { standards }\end{array}$ & $\begin{array}{c}\mathrm{SOM} \\
(\mathrm{g} / \mathrm{kg})\end{array}$ & $\begin{array}{c}\mathrm{TN} \\
(\mathrm{g} / \mathrm{kg})\end{array}$ & $\begin{array}{c}\mathrm{TP} \\
(\mathrm{g} / \mathrm{kg})\end{array}$ & $\begin{array}{c}\mathrm{TK} \\
(\mathrm{g} / \mathrm{kg})\end{array}$ & $\mathrm{pH}<7.0$ & $\mathrm{pH}>7.0$ \\
\hline$X_{a}$ & 6 & 0.75 & 0.2 & 5 & 4.5 & 7 \\
$X_{c}$ & 20 & 1 & 0.6 & 10 & 5.5 & 8 \\
$X_{p}$ & 30 & 1.5 & 1 & 15 & 6.5 & 9 \\
\hline
\end{tabular}

$X_{a}, X_{c}$ and $X_{p}$ indicate the classification standard value for soil factors. 


\subsubsection{Nemerow Comprehensive Pollution Index Method}

Nemerow comprehensive pollution index method is a combination of single factor pollution index method and other evaluation methods, which can be used to evaluate mixed pollution caused by various factors at the same time. This method has been widely used in the assessment of mixed pollution due to the comprehensive consideration of the mean and minimum value of the single factor pollution index [17]. Its expression is:

$$
P=\sqrt{\left(\bar{P}_{i}^{2}+P_{\max }^{2}\right) / 2}
$$

where $P$ is Nemerow comprehensive pollution index; $\bar{P}_{i}$ is the average single factor pollution index; and $P_{\max }$ is the maximum single factor pollution index. The evaluation classification criteria of Nemerow comprehensive pollution index method was listed shown in Table 2.

\subsubsection{Geo-Accumulative Index Method}

Geo-accumulation index method is often used to quantitatively assess the degree of soil heavy metal pollution, which was proposed by Muller in 1969 [18]. Its formula was as follows:

$$
I_{\text {geo }}=\log _{2}\left(\frac{C_{i}}{1.5 B_{i}}\right)
$$

where $I_{g e o}$ is the geo-accumulation index value of a sample; $B_{i}$ is the background values of soil elements in Shandong Province; $C_{i}$ is the actual measured concentration of an element $i$. The classification criteria of geo-accumulation index method are shown in Table 3.

Table 2. The evaluation classification criteria for Nemerow comprehensive pollution index method.

\begin{tabular}{ccc}
\hline Level & Comprehensive pollution index & Pollution levels \\
\hline 1 & $P \leq 0.7$ & Cleanliness (Safety) \\
2 & $0.7<P \leq 1.0$ & Clean (warning line) \\
3 & $1.0<P \leq 2.0$ & Light pollution \\
4 & $2.0<P \leq 3.0$ & Moderate pollution \\
5 & $P>3.0$ & Heavy pollution \\
\hline
\end{tabular}

Table 3. The classification criteria of geo-accumulation index method.

\begin{tabular}{ccc}
\hline Level & Geo-accumulation index & Pollution levels \\
\hline 1 & $I_{g e o} \leq 0$ & No pollution \\
2 & $0 \leq I_{g e o} \leq 1$ & Slight pollution \\
3 & $1 \leq I_{g e o} \leq 2$ & Towards moderate pollution \\
4 & $2 \leq I_{g e o} \leq 3$ & Moderate pollution \\
5 & $3 \leq I_{g e o} \leq 4$ & Towards serious pollution \\
6 & $4 \leq I_{g e o} \leq 5$ & Serious pollution \\
7 & $I_{g e o}>5$ & Extremely serious pollution
\end{tabular}




\subsection{Data Processing}

The distribution map of sampling sites and the spatial distribution map of soil indicators in the study area were drawn using ArcGIS 10.2; the descriptive statistical analysis of soil indicator content was carried out using SPSS 19.0; the calculation of soil fertility coefficient and soil heavy metal pollution index, as well as the production of related tables and charts were completed using Excel.

\section{Results}

\subsection{Soil Fertility in the Dawen River Basin}

\subsubsection{Characteristics of Soil Nutrient Content}

Table 4 listed the statistical characteristics of the soil nutrient content at 107 points in the Dawen River Basin. The soil pH was between 4.68 and 8.32; the content of SOM ranged from 3.08 to $31.80 \mathrm{~g} / \mathrm{kg}$; the TN ranged from 0.8 to 1.29 $\mathrm{g} / \mathrm{kg}$; the TP ranged from 0.07 to $1.73 \mathrm{~g} / \mathrm{kg}$; and the TK ranged from 2.72 to 11.07 $\mathrm{g} / \mathrm{kg}$. The coefficient of variation of TP was the largest (0.58), indicating that the TP content in the Dawen River basin exhibited the greatest variability, followed by the SOM and TK.

According to the Nutrient Classification Standard for the Second National Soil Survey, the content levels of the SOM, TN, TP, and TK at the 107 sampling sites in the Dawen River Basin was graded separately (Figure 2). The SOM content of most of the sample points belongs to the fourth level (68 points), followed by the third level ( 27 points) and the fifth level ( 9 points); the TN content of most soil points was mainly distributed in the third level (68 points), followed by level four (39 points); the total phosphorus content and total potassium content of the soil at most points belong to the fifth level. On the whole, the soil nutrient content of the Dawen River basin is medium and below.

\subsubsection{Spatial Distribution of Soil Nutrient}

Figure 3 shows the spatial distribution of soil nutrient content at 107 sample sites in the Dawen River Basin. The larger the point, the higher the nutrient content. On the whole, there is no obvious spatial trend in soil nutrient content. The areas with relatively high soil nutrient content in the Dawen River Basin were distributed in the southeast of Taian City, the northwest of Xintai City and the north of Ningyang County.

Table 4. Statistics of soil nutrient content of the Dawen River Basin.

\begin{tabular}{cccccc}
\hline Items & $\mathrm{pH}$ & $\begin{array}{c}\mathrm{SOM} \\
(\mathrm{g} / \mathrm{kg})\end{array}$ & $\begin{array}{c}\mathrm{TN} \\
(\mathrm{g} / \mathrm{kg})\end{array}$ & $\begin{array}{c}\mathrm{TP} \\
(\mathrm{g} / \mathrm{kg})\end{array}$ & $\begin{array}{c}\mathrm{TK} \\
(\mathrm{g} / \mathrm{kg})\end{array}$ \\
\hline Max & 8.32 & 31.80 & 1.29 & 1.73 & 11.07 \\
Min & 4.68 & 3.08 & 0.80 & 0.07 & 2.72 \\
Mean & 7.06 & 16.66 & 1.05 & 0.48 & 6.14 \\
Coefficient of variation & 0.12 & 0.34 & 0.14 & 0.58 & 0.26 \\
\hline
\end{tabular}




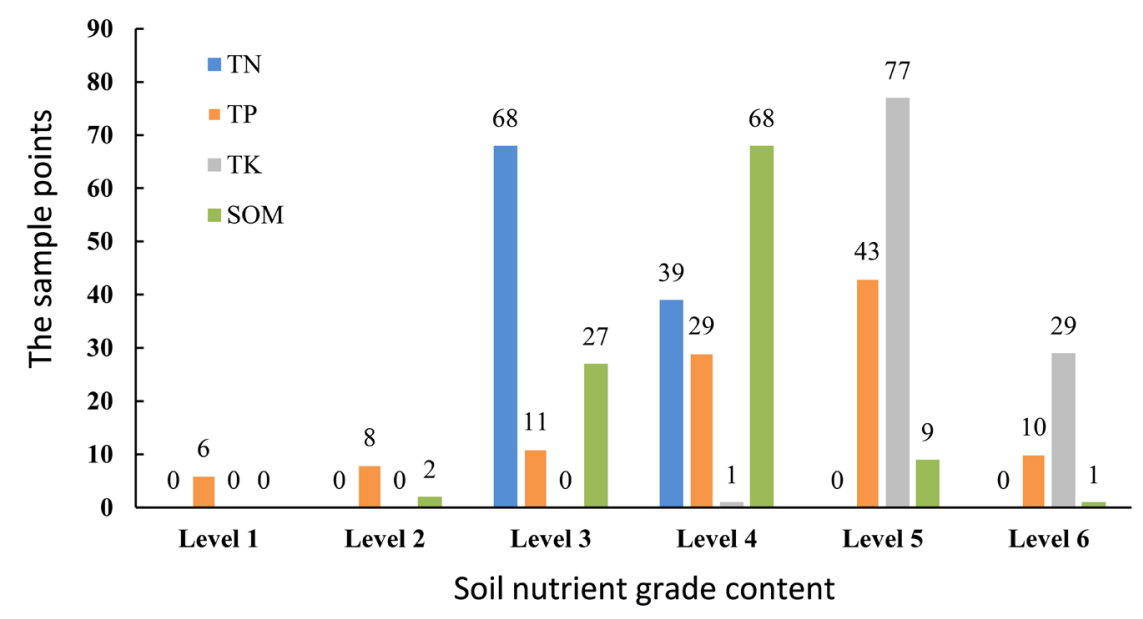

Figure 2. Classification characteristics of soil nutrient content in the Dawen River Basin.
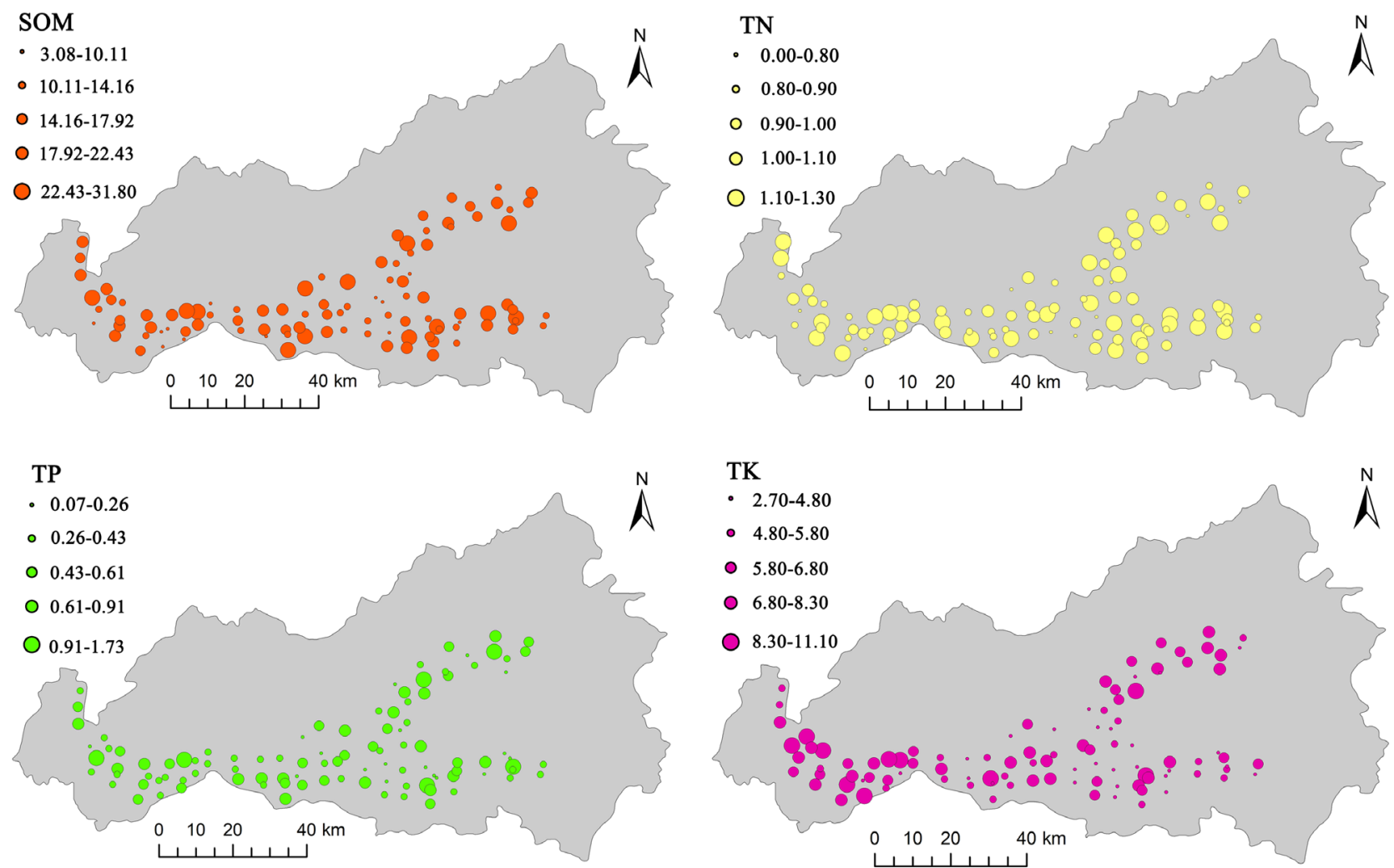

Figure 3. Spatial distribution of soil nutrient content in the Dawen River Basin.

\subsubsection{Comprehensive Evaluation of Soil Fertility}

5 soil indicators, including $\mathrm{pH}, \mathrm{SOM}$, TN, TP, and TK, were selected as evaluation indices to comprehensively evaluate the soil fertility in the Dawen River Basin. The comprehensive soil fertility coefficient at the 107 soil points were calculated according to the revised formula of the Nemerow index method. To reveal the spatial characteristics of soil fertility in the basin, the soil comprehensive fertility coefficient of the 107 sample points was interpolated using ordinary Kriging interpolation method, and was classified based on a soil fertility grading 
standard (Table 5).

It can be seen from Figure 4 that the soil fertility in Dongping and Ningyang was at a general level; most of the soil in Taian city and Feicheng belongs to the general fertility level, and a small part was at the barren fertility level; the soil fertility in Xintai City and the southern part of Laiwu is at a barren state. On the whole, the comprehensive soil fertility of the Dawen River Basin is at a general level or below, which is consistent with the previous analysis that the soil nutrient in the Dawen River Basin was at a medium or below level.

\subsection{Present Situation of Heavy Metal Pollution in Dawen River Basin}

\subsubsection{Characteristics of Soil Heavy Metal Content}

According to the soil pollution risk value specified in the Soil Environmental Quality Risk Control Standard for Soil Contamination of Agricultural Land of China (GB 15618-2018), the soil heavy metal content of 107 points was grouped according to different $\mathrm{pH}$ ranges (Table 6). The soil Cd content at the 107 points in the Dawen River basin was between $0.07-0.28 \mathrm{mg} / \mathrm{kg}$; the content of $\mathrm{Hg}$ was distributed between $0-0.17 \mathrm{mg} / \mathrm{kg}$; the content of As lay between $3.34-34.44$ $\mathrm{mg} / \mathrm{kg}$; the content of $\mathrm{Pb}$ was distributed $19.46-39.41 \mathrm{mg} / \mathrm{kg}$; and content of $\mathrm{Cr}$ ranged from 24.00 to $495.25 \mathrm{mg} / \mathrm{kg}$. By comparing the soil heavy metal content of each group with the corresponding risk value, it was found that only two points of heavy metal content exceeded the standard. One point is located in South bank of the confluence of Muwen River and Yingwen River, where soil Cr content was $495.25 \mathrm{mg} / \mathrm{kg}$; The other point is located on the south bank of Chaiwen River, near Gongli Town of Xintai city, where soil As content was 34.44

Table 5. Soil comprehensive fertility grading standards.

\begin{tabular}{ccccc}
\hline Level & Very fertile & Fertile & General & Barren \\
\hline$P$ & $P \geq 2.70$ & $1.80 \leq P<2.70$ & $0.90 \leq P<1.80$ & $P<0.90$ \\
\hline
\end{tabular}

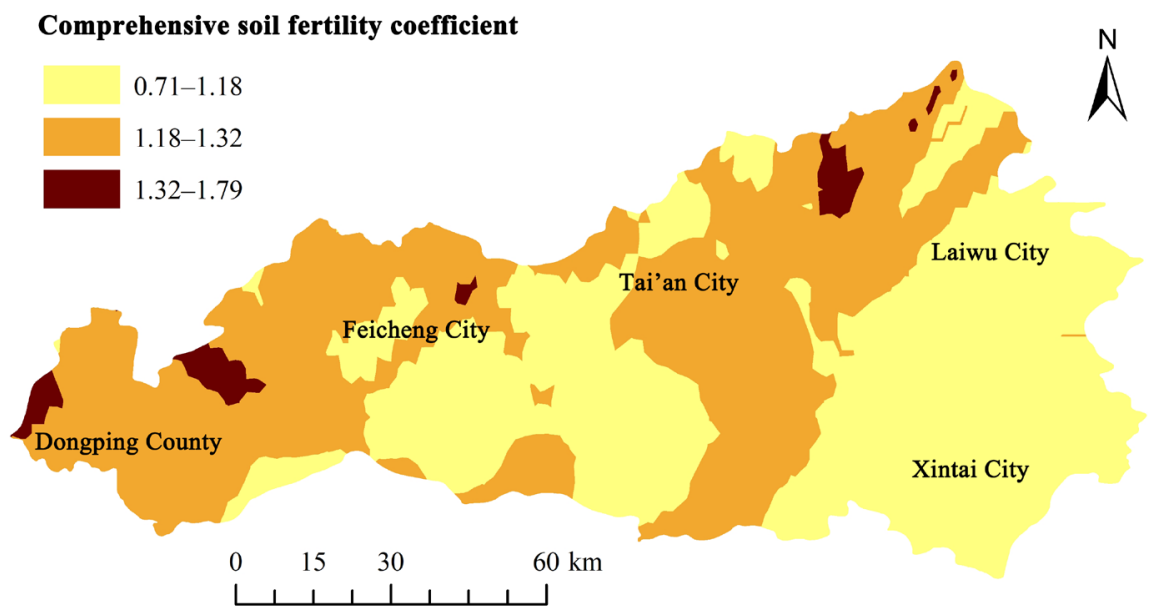

Figure 4. Spatial distribution of soil fertility in the Dawen River Basin. 
Table 6. Statistics of soil heavy metal content in the Dawen River Basin (mg/kg).

\begin{tabular}{|c|c|c|c|c|c|}
\hline $\mathrm{pH} \leq 5.5$ (4 points) & $\mathrm{Cd}$ & $\mathrm{Hg}$ & As & $\mathrm{Pb}$ & $\mathrm{Cr}$ \\
\hline $\operatorname{Max}$ & 0.16 & 0.06 & 13.90 & 33.23 & 495.25 \\
\hline Min & 0.10 & 0.01 & 7.76 & 20.73 & 30.81 \\
\hline Mean & 0.14 & 0.03 & 11.04 & 25.56 & 159.67 \\
\hline Coefficient of variation & 0.14 & 0.67 & 0.22 & 0.19 & 1.22 \\
\hline Risk value & 0.30 & 1.30 & 40.00 & 70.00 & 150.00 \\
\hline $5.5<\mathrm{pH} \leq 6.5$ (21 points) & $\mathrm{Cd}$ & $\mathrm{Hg}$ & As & $\mathrm{Pb}$ & $\mathrm{Cr}$ \\
\hline $\operatorname{Max}$ & 0.20 & 0.11 & 23.80 & 36.36 & 66.81 \\
\hline Min & 0.07 & 0.005 & 3.34 & 19.45 & 28.16 \\
\hline Mean & 0.13 & 0.03 & 10.52 & 26.16 & 45.94 \\
\hline Coefficient of variation & 0.31 & 1 & 0.45 & 0.15 & 0.21 \\
\hline Risk value & 0.30 & 1.80 & 40.00 & 90.00 & 150.00 \\
\hline $6.5<\mathrm{pH} \leq 7.5$ (45 points) & $\mathrm{Cd}$ & $\mathrm{Hg}$ & As & $\mathrm{Pb}$ & $\mathrm{Cr}$ \\
\hline Max & 0.28 & 0.14 & 20.85 & 37.76 & 84.24 \\
\hline Min & 0.08 & 0.007 & 3.77 & 20.40 & 24.53 \\
\hline Mean & 0.14 & 0.03 & 10.17 & 27.52 & 52.56 \\
\hline Coefficient of variation & 0.29 & 0.67 & 0.38 & 0.14 & 0.22 \\
\hline Risk value & 0.30 & 2.40 & 30.00 & 120.00 & 200.00 \\
\hline $\mathrm{pH}>7.5$ (37 points) & $\mathrm{Cd}$ & $\mathrm{Hg}$ & As & $\mathrm{Pb}$ & $\mathrm{Cr}$ \\
\hline Max & 0.26 & 0.17 & 34.44 & 39.41 & 76.71 \\
\hline Min & 0.08 & 0.00 & 3.88 & 20.49 & 29.80 \\
\hline Mean & 0.15 & 0.03 & 10.10 & 28.80 & 54.90 \\
\hline Coefficient of variation & 0.27 & 1 & 0.50 & 0.14 & 0.19 \\
\hline Risk value & 0.60 & 3.40 & 25.00 & 170.00 & 250.00 \\
\hline
\end{tabular}

$\mathrm{mg} / \mathrm{kg}$. According to the coefficient of variation, the soil $\mathrm{Hg}$ content in the Dawen River Basin has a large variability in the spatial distribution, and the spatial difference of the soil $\mathrm{Cr}$ content with $\mathrm{pH}$ less than 5.5 was also large.

\subsubsection{Spatial Distribution of Soil Heavy Metal}

The spatial distribution of 5 soil heavy metals $(\mathrm{Cr}, \mathrm{Cd}, \mathrm{Pb}, \mathrm{As}$, and $\mathrm{Hg})$ in the Dawen River basin was obtained by interpolating the soil heavy metal content of 107 samples using ordinary Kriging interpolation method (Figure 5). The 5 soil heavy metals presented different spatial distribution patterns. The content of $\mathrm{Cr}$ was higher in the southeast of Taian City; the high-value areas of soil Cd were mainly distributed in Dongping County and Laiwu city; high-value points of As and $\mathrm{Pb}$ were concentrated in Taian and Laiwu city, and high-value areas of $\mathrm{Hg}$ was mainly concentrated in Taian city. Overall, the denser the urban and industrial distribution, the higher the content of heavy metals. 

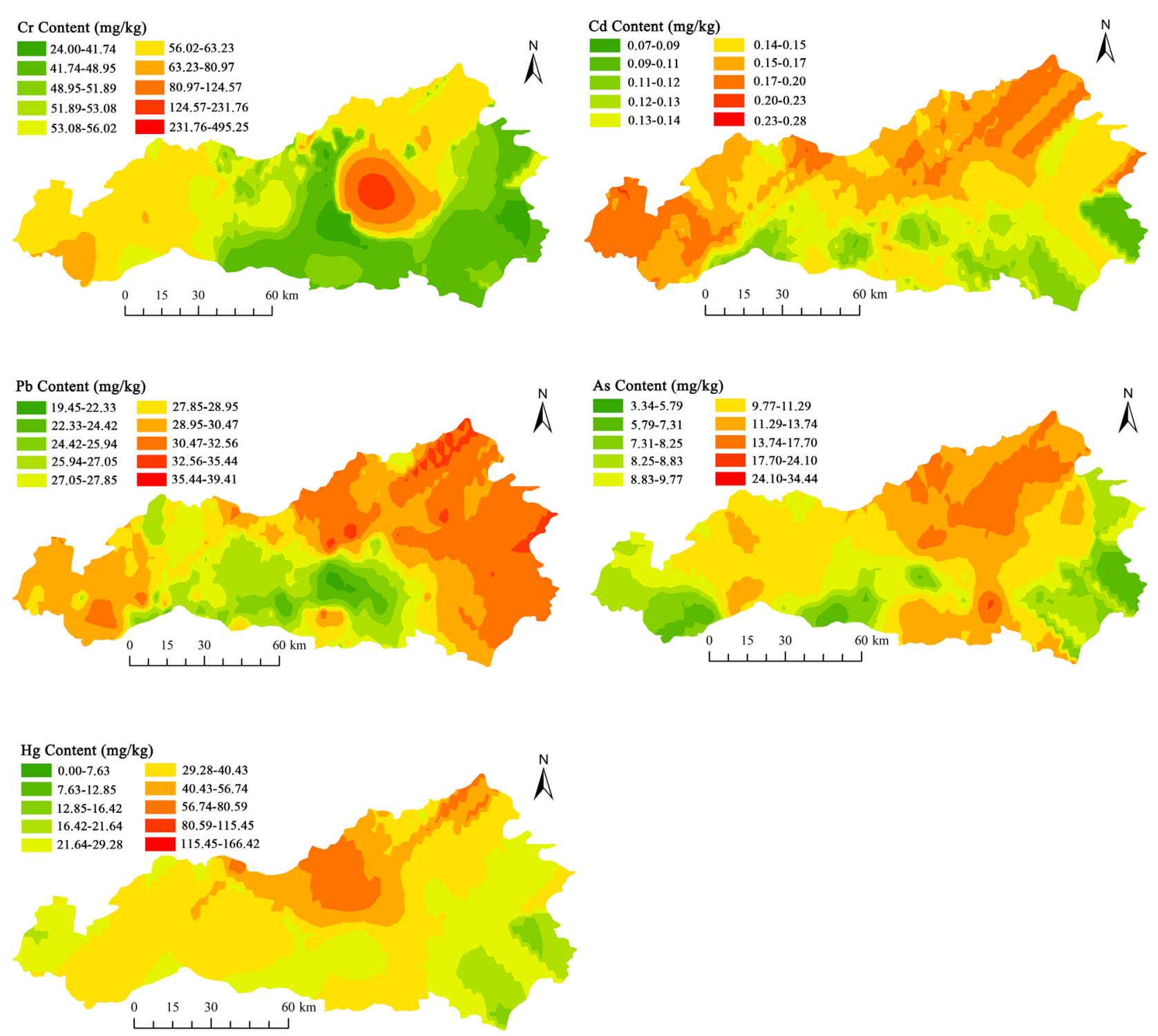

Figure 5. Spatial distribution of soil heavy metal content in the Dawen River Basin.

\subsubsection{Evaluation of Soil Heavy Metal Pollution}

The pollution status of soil heavy metals at the 107 points was evaluated using the Nemerow comprehensive pollution index (Table 7). The results showed that 105 out of the 107 points (98.14\%) belonged to the safety level, indicating that the surface soil of the Dawen River Basin was basically at a safety level. Besides, there was one point where the soil was at a light pollution level, and one point was at a moderate pollution level. There was no points with heavy pollution. The evaluation results showed that most of the soil in the Dawen River Basin is at a safe level and has little impact on the planting and production of the surrounding farmland.

The geo-accumulation index method was also used to evaluate the soil pollution at the sample sites, and the results were shown in Table 8. Compared with the background value of soil elements in Shandong Province, the 107 soil points 
Table 7. Evaluation results of the Nemerow comprehensive pollution index.

\begin{tabular}{ccc}
\hline Pollution levels & Number of sample points & Proportion (\%) \\
\hline Safety & 105 & 98.14 \\
warning line & 0 & 0 \\
Light pollution & 1 & 0.93 \\
Moderate pollution & 1 & 0.93 \\
Heavy pollution & 0 & 0 \\
\hline
\end{tabular}

Table 8. Evaluation results of geo-accumulation index method.

\begin{tabular}{ccccccc}
\hline & \multicolumn{5}{c}{ Proportion of sample points (\%) } & Index \\
\cline { 2 - 5 } Element & No pollution & $\begin{array}{c}\text { Slight } \\
\text { pollution }\end{array}$ & $\begin{array}{c}\text { Towards moderate } \\
\text { pollution }\end{array}$ & $\begin{array}{c}\text { Moderate } \\
\text { pollution }\end{array}$ & average & maximum \\
\hline $\mathrm{Cr}$ & 99.07 & 0 & 0 & 0.93 & -0.86 & 2.41 \\
$\mathrm{Cd}$ & 91.59 & 8.41 & 0 & 0 & -0.55 & 0.49 \\
$\mathrm{~Pb}$ & 96.53 & 3.74 & 0 & 0 & -0.38 & 0.15 \\
$\mathrm{As}$ & 78.51 & 20.56 & 0.93 & 0 & -0.46 & 1.42 \\
$\mathrm{Hg}$ & 89.72 & 7.48 & 2.8 & 0 & -0.89 & 1.84 \\
\hline
\end{tabular}

in the Dawen River Basin exhibited varying degrees of heavy metal pollution. For the heavy metal $\mathrm{Cr}$, only one site had moderate $\mathrm{Cr}$ pollution, and the other sites were all at non-polluting level; $8.41 \%$ of the sites were slightly contaminated with $\mathrm{Cd}$, but the pollution degree was very light as the maximum index was only $0.49 ; 3.74 \%$ of the sites had slight $\mathrm{Pb}$ pollution, the maximum index of which was only 0.15 , and its pollution degree was second to Cd; $20.56 \%$ of the sites had slight pollution of As, and only 1 sample showed towards moderate As pollution; $7.48 \%$ and $2.8 \%$ of the sites were slightly and moderately polluted by Hg. Notably, the average index of these 5 heavy metals were all less than zero, indicating that the soil in the basin was basically uncontaminated.

\section{Discussion}

The evaluation result of the Nemerow comprehensive pollution index, which uses the soil pollution risk value of agricultural land as the evaluation standard, showed that the current surface soil environmental quality of the Dawen River basin is relatively good, and only a few points have abnormally exceeded values. This requires subsequent sampling and analysis to determine whether the abnormally high values were caused by experimental errors or whether there was indeed heavy metal contamination at this site. However, the soil pollution level in the Dawen River Basin evaluated by the geo-accumulation index method was higher than that reflected by Nemerow comprehensive index method. This is because the geo-accumulation index method comprehensively considers the influences from natural geological processes and human activities in various regions. In particular, it is worth pointing out that the determination of the back- 
ground value would have a great impact on the geo-accumulation index. This study selected the soil elemental background value of Shandong Province as the evaluation standard, which is much smaller than the risk value of agricultural land. Therefore, the evaluation result of the geo-accumulation index method has a higher degree of pollution, which is consistent with the study by Chen et al. [19].

There are more than 400 heavy-polluting enterprises, such as chemical industry, breeding, papermaking, printing and dyeing, textile, etc., in the Dawen River basin. Some enterprises have insufficient scale of sewage treatment facilities and cannot stably meet the discharge standards. Besides, the discharge of rural domestic sewage and wastewater from livestock and poultry breeding, and the extensive use of chemical fertilizers, pesticides, agricultural films, and growth regulators, would also cause heavy metal pollution in the soil. Therefore, it is necessary to take certain measures to protect the soil environment in the Dawen River Basin. It mainly includes 1) shutting down and transforming heavily polluting enterprises to increase the sewage treatment rate; 2) establishing complete sewage discharge, collection and deep purification facilities; 3) strictly controlling the direct discharge of domestic sewage and improving rural sewage treatment facilities; 4) Strictly controlling the quality and dosage of pesticides and fertilizers, promoting precise fertilization to improve fertilization efficiency.

\section{Conclusions}

This paper evaluated the soil fertility and heavy metal pollution in the Dawen River Basin based on 107 soil samples. The results indicated that the soil fertility in the Dawen River Basin was mainly at general and barren levels, and the soil TN had the highest content level. There is no obvious spatial distribution trend of soil nutrients, but it can be seen that the soil nutrient level in the southeast of Taian city, the northwest of Xintai city, and the northern part of Ningyang county was relatively high.

The statistical results of soil heavy metal content showed that $98.14 \%$ of the samples had heavy metal content less than the corresponding risk value, and only two samples had excessive $\mathrm{Cr}$ and As content, which was consistent with the evaluation result of Nemerow comprehensive pollution index method. While the geo-accumulation index showed that some sites have slight pollution of $\mathrm{Cd}$, $\mathrm{Pb}, \mathrm{As}$, and $\mathrm{Hg}$ in the soil. Soil As and $\mathrm{Hg}$ exhibited towards moderate pollution at certain sample sites and a certain sample point appeared moderate pollution by $\mathrm{Cr}$. This difference was related to the different standard values used in the calculation. Spatially, the heavy metal content of soil is relatively high in the cities and industrial areas in the Dawen River Basin.

\section{Acknowledgements}

This study was supported by the Special Fund for Scientific Research of Shandong Bureau of Coal Geology (NO. 2019-8). 


\section{Fund Program}

Special Fund for Scientific Research of Shandong Bureau of Coal Geology (NO. 2019-8).

\section{Conflicts of Interest}

The authors declare no conflicts of interest regarding the publication of this paper.

\section{References}

[1] Sun, R.H., Wei, L.Y., Zhang, H.P. and Chen, L. (2020) Present Situation and Prospect of River Ecosystem Health Research-Based on Bibliometric Study. Journal of Ecology, 40, 3526-3536.

[2] Huang, Y. and Yang, Z. F. (2009) Foreign Research Progress of Soil Quality Evaluation. Geological Bulletin of China, 8, 130-136.

[3] Lu, S.J. and He, L.H. (2013) A Brief Talk on Soil Environmental Quality Monitoring. Environmental monitoring management and technology, 8, 8-12.

[4] Gao, Q. (2020) Eco-Hydrological Change Process and Prediction of Dawen River Basin, MA. Thesis, Jinan University, Jinan.

[5] Sigua, G.C. and Holtkamp, M.L. (2004) Assessing the Efficacy of Dredged Materials from Lake Panasoffkee, Florida, Implication to Environment and Agriculture. Part 1: Soil and Environmental Quality Aspect. PubMed Magazine, 6, 321-326.

[6] Sigua, G.C. and Holtkamp, M.L. (2004) Assessing the Efficacy of Dredged Materials from Lake Panasoffkee, Florida, Implication to Environment and Agriculture. Part 2: Pasture Establishment and Forage Productivity. PubMed Magazine, 11, 394-399. https://doi.org/10.1007/BF02979659

[7] Marrugo, N.J.,Pinedo, H.J. and Diez, S. (2017) Assessment of Heavy Metal Pollution, Spatial Distribution and Origin in Agricultural Soils along the Sinu River Basin, Colombia. Environmental Research, 154, 380-388. https://doi.org/10.1016/j.envres.2017.01.021

[8] Liu, Z.F., Fu, B.J., Liu, G.H., et al. (2006) Soil Quality and Soil Index along River Coast and Its Evaluation. Journal of Ecology, 26, 901-914.

[9] Liang, B., Yang, Y.J., Wang, C.L., et al. (2016) Heavy Metal Pollution and Ecological Risk Assessment of the Soil along the River in the High Environmental Risk Area of Yongqiao. Bridge Journal of Applied and Environmental Biology, 22, 257-262.

[10] Wen, J.H. (2019) Study on River Health Evaluation and Ecological Regulation in Dawen River Basin. MA. Thesis, Jinan University, Jinan.

[11] Qi, Z.H. (2017) Water Ecosystem Evaluation and Water Ecological Civilization Construction in Dawen River Basin. MA. Thesis, Jinan University, Jinan.

[12] Shen, Q., Wei, J., Wu, W., et al. (2020) The Correlation between the Water Ecological Environment Health Status and Land Use of Dawen River. Journal of Ecology, $39,224-233$

[13] Wen, J.H., Xu, Z.H., Wu, W., et al. (2018) Study on Health Assessment of Aquatic Ecosystem in Dawen River Basin. South-to-North Water Diversion and Water Conservancy Technology, 16, 118-124.

[14] Xia, J.Y., Zhong, P., Liu, C., et al. (2017) Analysis on the Evolution Characteristics of Precipitation in the Dawen River Basin in the Past 58 years. Hydropower Energy 
Science, 35, 6-10.

[15] Zhang, C.L., Wang, W.M., Cheng, H., et al. (2017) Analysis of Flood Characteristics of Dawenkou (Linwen) Hydrological Station in Dawen River. Water Conservancy Technology and Economy, 23, 50-54.

[16] Yang, L. (2019) Analysis of Soil Factors and Quality Evaluation of Slope Soil in Coal Mine Subsidence Area in Northern Shaanxi. MA. Thesis, Xi'an University of Science and Technology, Xi'an.

[17] Li, C.F., Wong, F., Cao W.T., et al. (2017) Sources, Spatial Distribution and Pollution Evaluation of Heavy Metals in Farmland in Sewage Irrigation Area of Longkou City. Environmental Science, 38, 1018-1027.

[18] Zhang, L., Qin, Y.W., Ma, Y.Q., et al. (2014) Spatial Distribution and Pollution Evaluation of Heavy Metals in the Tidal Section of the Daliao River and Its Coastal Estuary. Environmental Science, 35, 3336-3345.

[19] Chen, W.X., Li, X., Wang, Z., et al. (2020) Spatial Distribution Characteristics and Pollution Evaluation of Heavy Metals in Farmland Soils in China. Environmental Science, 41, 320-331. 